\title{
Effects of Fill Volume and Humidification on Aerosol Delivery During Single-Limb Noninvasive Ventilation
}

\author{
Haitham Saeed, Marwa Mohsen, Abeer Salah Eldin PhD, Ahmed A Elberry PhD, \\ Raghda RS Hussein PhD, Hoda Rabea PhD, and Mohamed EA Abdelrahim PhD
}

\begin{abstract}
BACKGROUND: The aim of this work was to determine the effect of fill volume and humidification change on aerosol delivery during single-limb noninvasive ventilation (NIV). METHODS: Four groups were recruited, each consisting of 12 subjects ( 6 females) with COPD receiving NIV. Groups 1 and 3 received inhaled salbutamol with a vibrating mesh nebulizer, and Groups 2 and 4 received inhaled salbutamol with a jet nebulizer. The in vivo study was carried out on days 1 and 3. In groups 1 and 2, 2 fill-volumes were delivered to each subject; $1 \mathrm{~mL} 5,000 \mu \mathrm{g} / \mathrm{mL}$ salbutamol respirable solution used as it is or diluted to a total of $2 \mathrm{~mL}$ using normal saline. In groups 3 and 4,

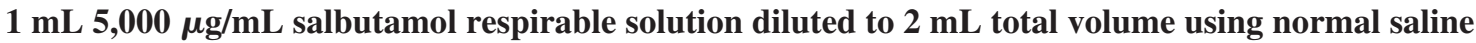
was delivered to each subject with and without humidification. Unchanged salbutamol in urine at $30 \mathrm{~min}$ (USAL0.5) and in pooled urine at $24 \mathrm{~h}$ (USAL24) was determined. On day 2, the ex vivo study was carried out on subjects using the same experimental setting with a filter placed proximal to their face mask for collection of total inhaled dose of salbutamol (aerosol emitted). RESULTS: The vibrating mesh nebulizer delivered higher USAL0.5, USAL24, and aerosol emitted compared to the jet nebulizer at all fill volumes and humidification conditions $(P<.001)$. Increasing fill volume from $1 \mathrm{~mL}$ to $2 \mathrm{~mL}$ resulted in a significant increase in USAL0.5, USAL24, and aerosol emitted from the jet nebulizer $(P<.05)$ with an insignificant effect on the vibrating mesh nebulizer. A 2-mL fill volume with the jet nebulizer delivered USAL24 and aerosol emitted comparable to those of $1 \mathrm{~mL}$ with the vibrating mesh nebulizer with significantly longer nebulization times $(P<.001)$. Humidification had an insignificant effect on aerosol delivery. CONCLUSIONS: Increasing the fill volume of a jet nebulizer is essential to increase the amount of inhaled medication reaching a subject. In contrast, there is no need to increase fill volumes when using a vibrating mesh nebulizer. There is no need to switch off the humidifier while delivering aerosol through a singlelimb NIV circuit. Key words: nebulizer; noninvasive ventilation; fill volume; humidification; urinary salbutamol; filter. [Respir Care 2018;63(11):1370-1378. (c) 2018 Daedalus Enterprises]
\end{abstract}

Introduction

Noninvasive ventilation (NIV) is a very good tool to reduce the incidence of intubation. ${ }^{1,2}$ In some situations,

Mr Saeed, Ms Mohsen, and Drs Hussein, Rabea, and Abdelrahim are affiliated with the Clinical Pharmacy Department, Faculty of Pharmacy, Beni-suef University, Beni-suef, Egypt. Dr Eldin is affiliated with the Respiratory Department, Faculty of Medicine, Beni-suef University, Benisuef, Egypt. Dr Elberry is affiliated with Clinical Pharmacology Faculty of Medicine, Beni-suef University, Beni-suef, Egypt. Dr Abdelrahim is also affiliated with the Clinical Pharmacy Department, Faculty of Pharmacy, Modern University for Technology and Information, Cairo, Egypt.
NIV may extend to several days and require aerosol delivery, which has been shown to be beneficial during NIV.2,3 In the last decade, aerosol delivery in NIV has been well studied. ${ }^{4-7}$ The type and position of the aerosol generator,

\footnotetext{
Dr Abdelrahim discloses a relationship with Aerogen. The other authors have disclosed no conflicts of interest.

Correspondence: Mohamed E A Abdelrahim PhD, Department of Clinical Pharmacy, Modern University for Technology and Information, Al Abageyah, Qism El-Khalifa, 12055 Cairo, Egypt. E-mail: mohamedemam9@yahoo.com.
}

DOI: $10.4187 /$ respcare.06022 
ventilator settings during aerosol delivery, and other variables during NIV have been investigated., ${ }^{4,5}, 7-18$

Many previously published studies recommended switching off the humidifier while delivering aerosol for improved aerosol delivery. $9,19,20$ However, we have shown that there was no significant effect on delivered aerosol associated with this practice during auto-CPAP or duallimb ventilation. ${ }^{16,21,22}$ In addition, turning off the humidifier and delivering dry gas may be harmful to the lungs, so it is imperative that the humidifier be turned on again after aerosol delivery is complete. ${ }^{4,23}$

Additionally, no studies were found regarding the recommended fill volume of the respiratory solutions placed in the nebulizer medication reservoir. These data would be helpful in determining whether we can improve aerosol delivery with larger fill volumes. It is also important to know which aerosol generators would be affected by increasing fill volumes because they function differently and have different residual volumes..$^{9,24,25}$ For example, the jet nebulizer, the most common type of nebulizer due to its low cost, has a very large residual volume $(\sim 0.7 \mathrm{~mL})$ compared to the low residual volume of vibrating mesh nebulizers $(\sim 0.1 \mathrm{~mL}))^{11,13,26}$

The aim of this study was to determine the effect of fill volume and humidification on aerosol delivery to subjects with a single-limb NIV circuit as a step toward optimizing aerosol delivery for mechanically ventilated patients while developing a foundation for practical guidelines.

Based on our previous in vitro study ${ }^{26}$ our hypothesis was that the fill volume change would affect the delivered dose to the subject, whereas the humidity change would not have any significant effect.

\section{Methods}

This study was conducted in accordance with the amended Declaration of Helsinki. A local hospital research ethics committee approval number was obtained for the subjects in the study (FM-BSU REC FWA: FWA00015574). Written informed consent was obtained from all subjects. The study was performed at the Teaching Hospital of Faculty of Medicine, Beni-suef University, Beni-suef, Egypt. Controllers and vibrating mesh nebulizers were supplied by Aerogen (Galway, Ireland).

Patients with a previous diagnosis of COPD who had been admitted to the respiratory unit with an exacerbation or who required NIV for respiratory acidosis and were prescribed salbutamol were eligible for study. All subjects were recruited using the hospital-approved delayed-consent procedure.

Patients were ineligible to be included in this study if they had taken part in a research study during the previous 6 months, had known hypersensitivity to salbutamol, presented with a systolic blood pressure

\section{QUICK LOOK}

\section{Current knowledge}

Current recommendations for aerosol delivery during mechanical ventilation include increasing the fill volume of the nebulizer and discontinuing humidity. The efficiency of aerosol delivery during non-invasive ventilation is impacted by position of the nebulizer relative to the leak port in the circuit.

\section{What this paper contributes to our knowledge}

Increasing the fill volume is an essential factor to improve aerosol delivery via jet nebulizer but not via vibrating mesh nebulizer. The use of humidity had no significant effect on aerosol delivery in single-limb noninvasive ventilation.

of $<100 \mathrm{~mm} \mathrm{Hg}$, or exhibited severe renal impairment defined as creatinine clearance or estimated glomerular filtration rate $<20 \mathrm{~mL} / \mathrm{min}$.

\section{Study Design and Procedures}

As shown in Figure 1, recruited subjects in the study were divided into 4 groups. Subjects were randomized to be included in one of these groups. We utilized block randomization with the use of http://www.randomization. com. Each group received nebulized salbutamol using either a vibrating mesh nebulizer (Aerogen Solo, Aerogen, Galway, Ireland) or a jet nebulizer (Sidestream, Philips Respironics, Guildford, United Kingdom), with predetermined conditions and settings for each group. These nebulizers, conditions, and settings were used in the in vivo and ex vivo parts of the study.

\section{In Vivo Method}

Hindle et $\mathrm{al}^{27}$ developed a urinary pharmacokinetic method to determine relative lung and systemic bioavailability of salbutamol after inhalation. This method used the amount of drug excreted in urine after $30 \mathrm{~min}$ as an index of lung deposition and the amount of drug excreted in urine over a 24-h period after inhalation as an index of systemic absorption. This noninvasive pharmacokinetic method has been used to detect lung deposition of aerosolized drugs to healthy volunteers, ${ }^{18,28}$ subjects admitted with an exacerbation of either asthma or COPD, ${ }^{29}$ as well as ventilated subjects. ${ }^{10,14,15,17,21}$ Similarly, we used this methodology to determine the effect of fill volume and humidification changes on lung deposition and systemic absorption of 2 different nebulizers. 
Fill Volume, Humidity, AND Aerosol Delivery With NIV

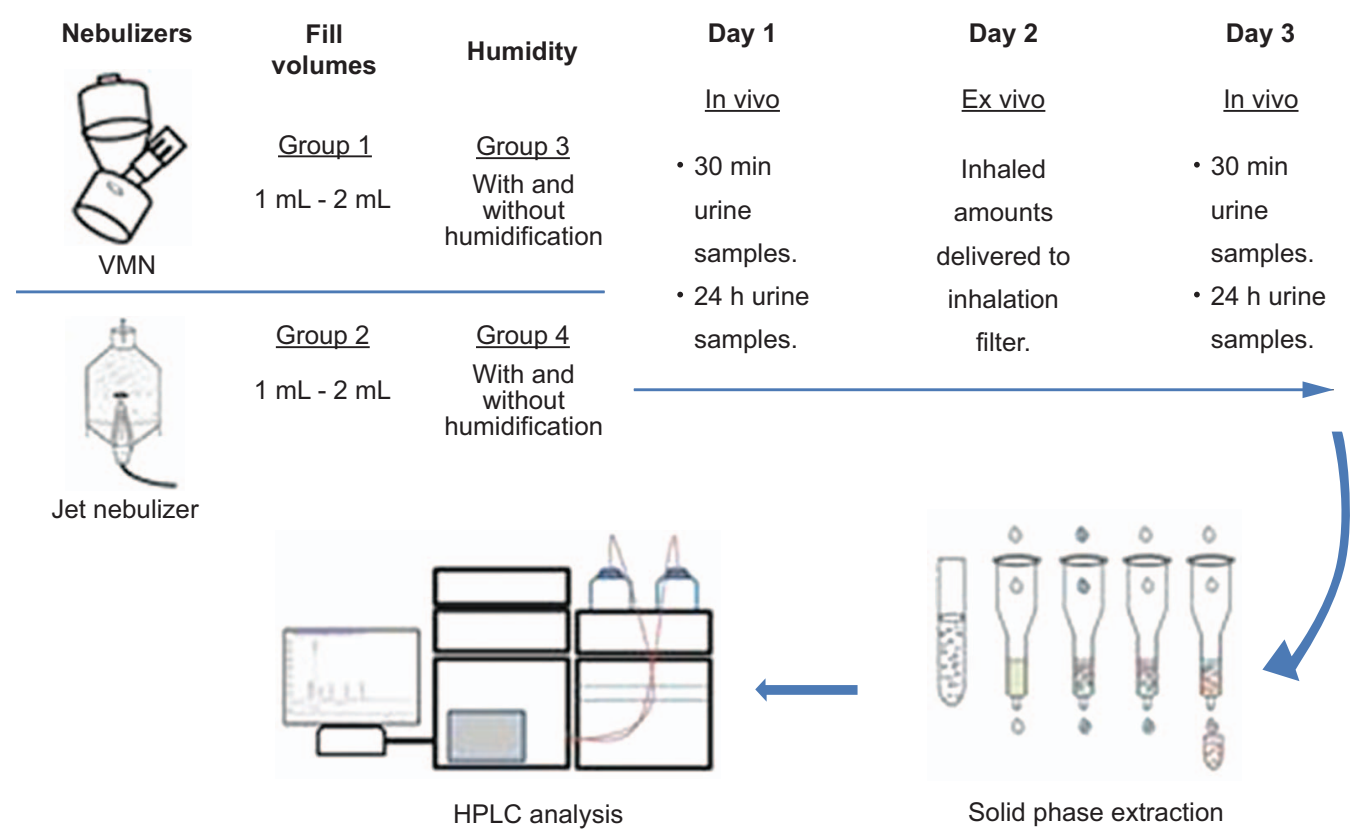

Fig. 1. Schematic design of the study ( $n=12$ for each group).

Bi-level ventilators are intended to provide airway support during breathing by blowing air into the lungs during a breathing cycle. Pressure is increased during the patient's inhalation to a set level, and it is then allowed to decrease to a threshold level when they breathe out, thus reducing the work of breathing. The bi-level ventilator (Breas Medical, Stratford-Upon-Avon, United Kingdom) was set in spontaneous mode at an inspiratory pressure of $20 \mathrm{~cm} \mathrm{H}_{2} \mathrm{O}$ and expiratory pressure of $5 \mathrm{~cm} \mathrm{H}_{2} \mathrm{O}$ according to the routine ward protocol. These ventilator pressures are the typical levels used for COPD patients. A schematic design of the study is shown in Figure 2.

The NIV breathing circuit (Fisher \& Paykel Healthcare, Auckland, New Zealand) consisted of a 180-cm length of corrugated tubing (diameter $22 \mathrm{~mm}$ ) with an integrated fixed-leak expiration port (Breas Medical, Stratford-UponAvon, United Kingdom). We placed the nebulizer near the subject between the face mask and the expiration port because this format has been shown to produce a greater aerosol delivery with less aerosol loss through the expiration port. ${ }^{11,30}$

Day 1 study doses occurred between 12 and $24 \mathrm{~h}$ after start of NIV. Salbutamol administration was avoided for at least $12 \mathrm{~h}$ prior start of the study. Subjects received ipratropium bromide (Atrovent inhalation solution containing a nominal dose of $25 \mu \mathrm{g} / \mathrm{mL}$, Boehringer Ingelheim, Ingelheim am Rhein, Germany) in place of their normal salbutamol dose during this period. The high-performance liquid chromatography analysis method that we used differentiated between these 2 drugs.

For the fill-volume part of the study, subjects were randomized to receive the salbutamol study doses via either vibrating mesh nebulizer (group 1) or jet nebulizer (group 2 ) attached to a compressor (PortaNeb, Philips Respironics) pre-set by the manufacturer at $6 \mathrm{~L} / \mathrm{min}$. In previous studies, the vibrating mesh nebulizer and the jet nebulizer were reported to have an average dead volume of $\sim 0.1$ and $0.7 \mathrm{~mL}$ respectively. ${ }^{11,13,26}$ Subjects were also randomized to receive the $5,000 \mu \mathrm{g}$ salbutamol study dose in a $1-$ or $2-\mathrm{mL}$ fill volume. The $2-\mathrm{mL}$ fill volume was prepared by placing $1 \mathrm{~mL}$ Farcolin respirator solution (5,000 $\mu \mathrm{g} / \mathrm{mL}$ salbutamol; Pharco Pharmaceuticals, Alexandria, Egypt) in the nebulizer medication reservoir and diluting it with $1 \mathrm{~mL}$ normal saline solution. In the fillvolume part of the study, the aerosol delivery occurred in dry non-humidified conditions.

For the humidification part of the study, subjects were again randomized to receive the salbutamol study doses via either vibrating mesh nebulizer (group 3) or jet nebulizer (group 4). They were also randomized to receive the salbutamol study dose with or without humidification, provided by a passover humidifier (MR810, Fisher \& Paykel Healthcare) with a single-limb NIV humidified circuit (Fisher \& Paykel Healthcare) as shown in Figure 2. The humidifier was set to invasive mode and allowed to reach $37 \pm 1^{\circ} \mathrm{C}$ prior to nebulization. A salbutamol dose of $5,000 \mathrm{ug} / \mathrm{mL}$ was given in the nebulizer medication reservoir along with 2 -mL fill volume containing $1 \mathrm{~mL}$ Farcolin respirator solution diluted with $1 \mathrm{~mL}$ normal saline.

Nebulization ended at sputter with the jet nebulizer and at dryness with the vibrating mesh nebulizer. Subjects voided urine $15 \mathrm{~min}$ before each study dose and then provided a urine sample $30 \mathrm{~min}$ (USAL0.5) from commencement of dosing. Their urine was then pooled for the next 


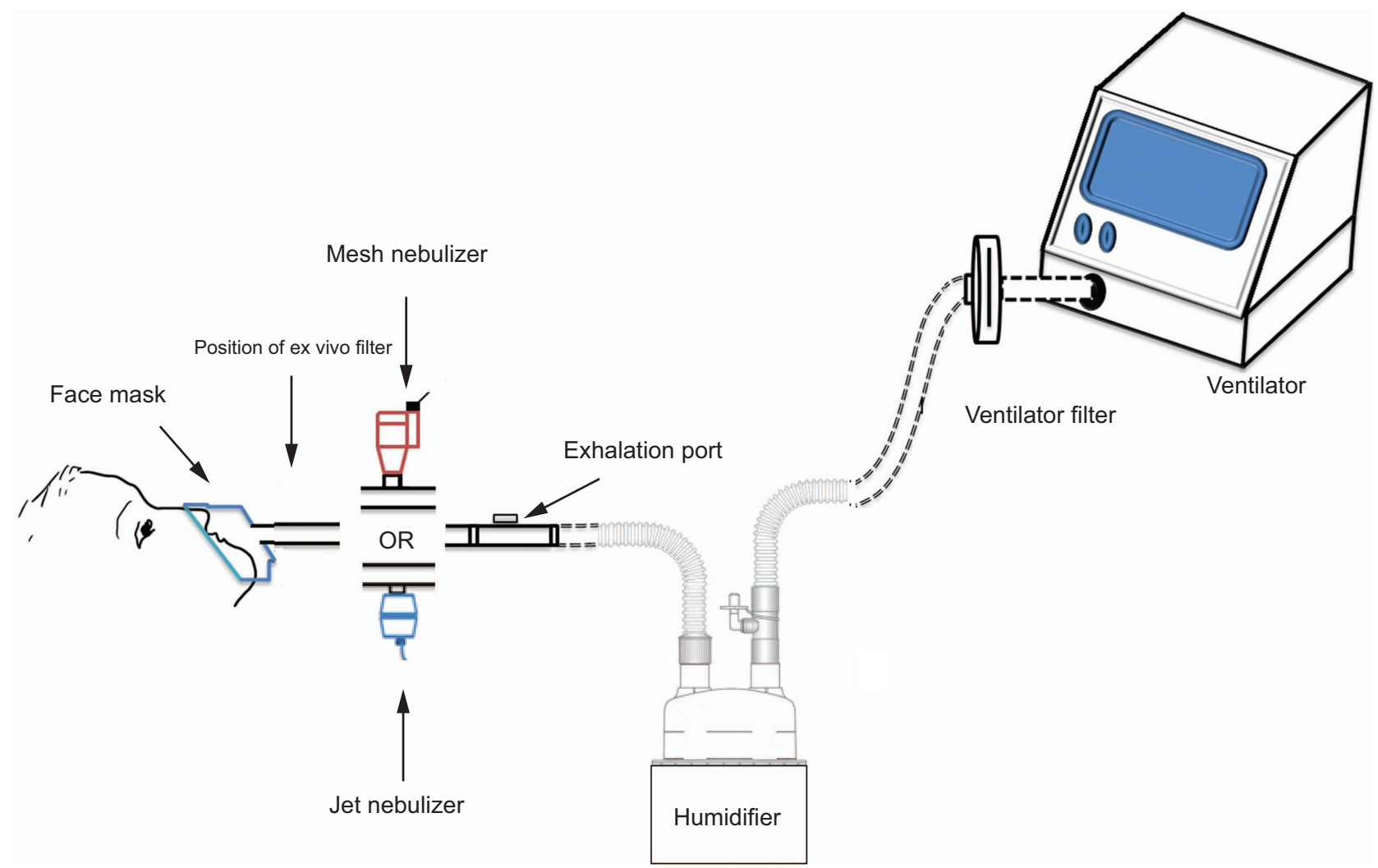

Fig. 2. Schematic design of the in vivo and ex vivo noninvasive ventilation methodology; in the ex vivo experimental setting, a filter was placed between the subject face mask and nebulizer.

$24 \mathrm{~h}$ (USAL24). The volume of 30-min and 24-h collection samples were measured and assayed for salbutamol using previously validated high-performance liquid chromatography. ${ }^{14,15,17,21,31}$ Salbutamol was extracted from urine samples using solid-phase extraction with Oasis MCX cartridge (Waters Corporation, Milford, Massachusetts), with bambuterol hydrochloride added as internal standard, and then injected into the high-performance liquid chromatography system. A 5- $\mu$ m octadecyl-silica (ODS) (4.6 $\mathrm{mm} \times 250 \mathrm{~mm}$, Zorbax Eclipse) C-18 high-performance liquid chromatography column with a $4 \mathrm{~mm} \times 3 \mathrm{~mm} \mathrm{C}-18$ (ODS) guard column (Agilent, Santa Clara, California) was used. Mobile-phase acetonitrile:water containing $0.1 \%$ orthophosphoric acid (90:10, v/v), was pumped through columns at flow of $1 \mathrm{~mL} / \mathrm{min}$ maintained at $25^{\circ} \mathrm{C}$, and photodiode array detection was set at $220 \mathrm{~nm}$. The lower limit of detection and lower limit of quantification for salbutamol were 0.36 and $1.00 \mu \mathrm{g} / \mathrm{mL}$, respectively.

\section{Ex Vivo Method}

On day 2, subjects received $5,000 \mu \mathrm{g} / \mathrm{mL}$ salbutamol in the previously described fill volumes or humidification conditions with either a vibrating mesh nebulizer or a jet nebulizer on a filter (Filta Guard breathing filter, Intersurgical, Wokingham, United Kingdom) placed between their face mask (AF531 oronasal mask, Philips Respironics, Guildford, United Kingdom) and nebulizer within the same setting shown in Figure 2. Previous studies have shown the ability of this filter to entrap all drugs that would reach the subject and to indicate percentage of loss. ${ }^{10,14,15,17}$ Subjects continued receiving their prescribed ipratropium bromide to relieve their bronchospasm during day 2 of the study because subjects did not receive any salbutamol during the ex vivo study. Salbutamol entrained on the filter was described as total inhaled dose (aerosol emitted) and assayed for salbutamol using previously validated highperformance liquid chromatography. ${ }^{12,13,25,26,32,33} \mathrm{We}$ used the $25 \mathrm{~mm} \times 4.6 \mathrm{~mm}$ Zorbax Eclipse Plus C18 and the ODS1 column (Agilant), through which the mobile phase consisted of a mixture of acetonitrile and water $(0.1 \%$ phosphoric acid) $(90: 10, \mathrm{v} / \mathrm{v})$ was pumped at $1 \mathrm{~mL} / \mathrm{min}$ using the 1260 Infinity preparative pump (G1361A, Agilant) the 1260 Infinity Diode array detector VL (G131SD, Agilant) was set at $225 \mathrm{~nm}$ with an injection volume $100 \mu \mathrm{L}$. Calibration solutions ranged from 4 to $100 \mu \mathrm{g} / \mathrm{mL}$ (weight/volume). Limit of detection was $0.35 \mu \mathrm{g} / \mathrm{mL}$, and the lower limit of quantification was $2.55 \mu \mathrm{g} / \mathrm{mL}$. 
Table 1. Demographic Data

\begin{tabular}{lllr}
\hline \hline & Age, y & Weight, kg & Height, cm \\
\hline Group 1 & $62.3(6.0)$ & $70.7(7.9)$ & $173(4.7)$ \\
Group 2 & $65.0(5.3)$ & $74.4(8.5)$ & $170.6(7.2)$ \\
Group 3 & $59.4(10.1)$ & $79.2(9.2)$ & $179(14.7)$ \\
Group 4 & $61.3(9.2)$ & $84.4(10.3)$ & $169.5(17.3)$ \\
\multicolumn{2}{l}{ Data are shown as mean (SD). } \\
\hline
\end{tabular}

\section{Data Analysis}

All data are expressed as mean (SD). The statistical analysis of the study was performed using SPSS version 22.0 (SPSS, Chicago, Illinois) with $P<.05$ considered significant. Mixed analysis of variation with the application of Bonferroni correction was used to compare both the urinary excretion of salbutamol and salbutamol on ex vivo filters post-inhalation.

\section{Results}

Forty-eight NIV subjects (24 females) recruited in the study were divided into 4 groups; each group consisted of 12 subjects (6 females). All of the subjects completed the study. The demographic data of the 4 groups are presented in Table 1. They all agreed to be included using a delayed consent procedure, and they completed all study doses. Routine ward management of these subjects does not include spirometery, so this was not measured.

Mean (SD) USAL0.5, USAL24, aerosol emitted, and nebulization times for jet nebulizer and vibrating mesh nebulizer with different fill volumes are shown in Table 2 and Figures 3-5.

No significant difference was found in USAL0.5, USAL24, and aerosol emitted between 1- and 2-mL fill volume with the vibrating mesh nebulizer. However, the 2 -mL fill volume resulted in significantly greater USAL0.5 $(P<.001)$, USAL24 $(P<.001)$, and aerosol emitted $(P<.001)$ than did the $1-\mathrm{mL}$ fill volume with the jet nebulizer.

The vibrating mesh nebulizer resulted in significantly greater USAL0.5 $(P<.001)$, USAL24 $(P<.001)$, and aerosol emitted $(P<.001)$ for all fill volumes studied. The vibrating mesh nebulizer with a $1-\mathrm{mL}$ fill volume resulted in significantly higher USAL0.5 $(P<.001)$ than did the jet nebulizer with a 2-mL fill volume. However, there was no significant difference between the vibrating mesh nebulizer with a $1-\mathrm{mL}$ fill volume and the jet nebulizer with a 2-mL fill volume for USAL24 and aerosol emitted.

Nebulization time with the 2-mL fill volume was significantly longer $(P<.001)$ than that with the $1-\mathrm{mL}$ fill volume for both the vibrating mesh nebulizer and the jet nebulizer. Nebulization times for 1- and 2-mL fill volume from the jet nebulizer were significantly longer $(P<.001)$ than those from the vibrating mesh nebulizer. No significant difference was found between nebulization times for the $1-\mathrm{mL}$ fill volume from the jet nebulizer and the 2-mL fill volume from the vibrating mesh nebulizer. Mean (SD) USAL0.5, USAL24, and aerosol emitted values for the jet nebulizer and the vibrating mesh nebulizer using different humidification conditions are shown in Table 3 and Figures 3-5.

Again, the vibrating mesh nebulizer resulted in significantly greater USAL0.5 $(P<.001)$, USAL24 $(P<.001)$ and aerosol emitted $(P<.001)$ compared to jet nebulizer for all humidification conditions studied. However, no significant difference was found between group 3 (jet nebulizer humidification) and group 4 (vibrating mesh nebulizer humidification) between humidified and dry conditions; there was an insignificant increase in the USAL24 and aerosol emitted in dry conditions.

\section{Discussion}

We studied the effect of humidification and increasing a nebulizer's loading volume from $1 \mathrm{~mL}$ to $2 \mathrm{~mL}$ for albuterol delivery in adult subjects with COPD treated with NIV and aerosols during an exacerbation. We used a previously described urinary pharmacokinetic method. ${ }^{27} \mathrm{We}$ found that humidity did not affect drug delivery. We also found that increasing the loading volume from $1 \mathrm{~mL}$ to $2 \mathrm{~mL}$ increased drug delivery in the jet nebulizer but not in the vibrating mesh nebulizer.

The great differences between the vibrating mesh nebulizer and the jet nebulizer when using a 1-mL fill volume (4.0 fold, 3.7 fold and 1.9 fold) were reduced to 2.8-, 1.3-, and 1.2-fold in USAL0.5, USAL24, and aerosol emitted, respectively, by increasing the fill volume to $2 \mathrm{~mL}$.

The jet nebulizer showed a significant $(P<.001)$ increase in the USAL0.5 (1.7-fold), USAL24 (2.9-fold), and aerosol emitted (1.8-fold) by increasing the fill volume. However, the vibrating mesh nebulizer showed an insignificant increase in the USAL0.5 (1.2-fold), USAL24 (1.1fold), and aerosol emitted (1.1-fold) by increasing the fill volume. The increase of the fill volume from $1 \mathrm{~mL}$ to $2 \mathrm{~mL}$ was very beneficial in the jet nebulizer compared to the vibrating mesh nebulizer, which may be due to the very small residual volume of the vibrating mesh nebulizer.9, $94,25,34$ This smaller residual volume allows the vibrating mesh nebulizer to deliver most of the respirable solution placed in the nebulizer reservoir. , $24,25,34$ This variation in the effect of fill-volume change for the jet nebulizer suggests that increasing the fill volume of a jet nebulizer improves its low efficiency. ${ }^{9,26,35}$

The trend of difference in the results of the in vivo study was similar to previous studies in single-limb $\mathrm{NIV}^{26}$ and 
Fill Volume, Humidity, AND Aerosol Delivery With NIV

Table 2. Salbutamol Delivered Using Different Fill Volumes

\begin{tabular}{lcccccc}
\hline \hline \multicolumn{1}{c}{ Nebulizer Type } & Fill Volume, $\mathrm{mL}$ & USAL0.5, $\mu \mathrm{g}$ & USAL24, $\mu \mathrm{g}$ & Ex vivo, $\mu \mathrm{g}$ & Time, min & Nebulization Chamber, $\mu \mathrm{g}$ \\
\hline Jet nebulizer & 1 & $28.3(7.6)$ & $146.3(42.3)$ & $792.9(130.7)$ & $3.42(0.08)$ & $2,927.9(887.7)$ \\
& 2 & $47.9(10.6)$ & $429.5(106.9)$ & $1,395(152.2)$ & $6.86(0.42)$ & $2,259.1(348.1)$ \\
$P$ & & $<.001$ & $<.001$ & $<.001$ & $<.001$ & .046 \\
Vibrating mesh nebulizer & 1 & $107.9(28)$ & $542.1(88.4)$ & $1,480.9(116.5)$ & $2.29(0.08)$ & $529.0(352.4)$ \\
& 2 & $134.6(44.7)$ & $599.6(60.9)$ & $1,690.8(156.0)$ & $4.22(0.7)$ & $257.2(76.9)$ \\
$P$ & & .70 & .73 & .78 & $<.001$ & .61
\end{tabular}

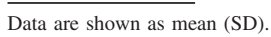

USAL0.5 $=$ unchanged salbutamol at $30 \mathrm{~min}$

USAL24 $=$ unchanged salbutamol at $24 \mathrm{~h}$

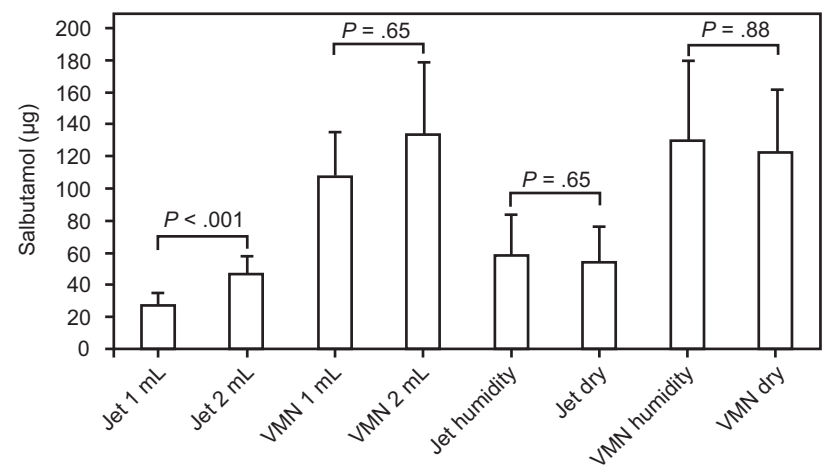

Fig. 3. Mean amounts of salbutamol excreted in urine after $30 \mathrm{~min}$. VMN $=$ vibrating mesh nebulizer.

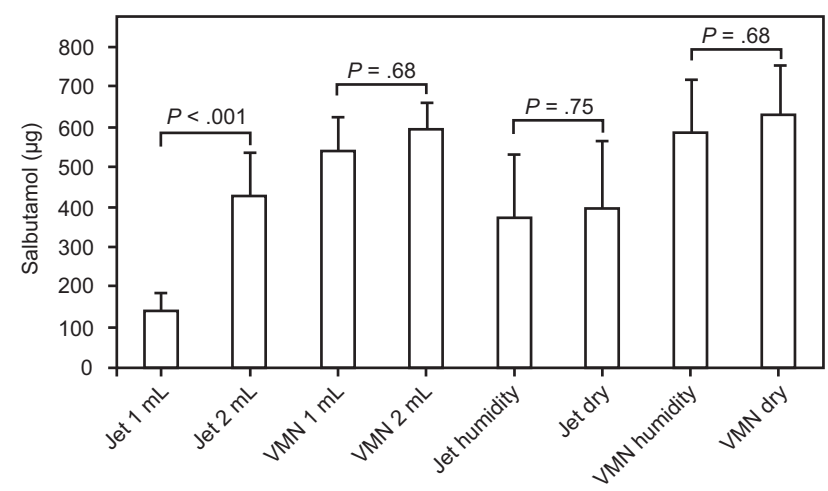

Fig. 4. Mean amounts of salbutamol excreted in urine after $24 \mathrm{~h}$. $\mathrm{VMN}=$ vibrating mesh nebulizer.

dual-limb ventilation. ${ }^{9,36-38}$ However, the magnitude of difference between the vibrating mesh nebulizer and the jet nebulizer and between 1 and $2 \mathrm{~mL}$ was much higher in the USAL0.5 and USAL24 measurements, whereas the aerosol emitted measurements increased in the same manner as what was observed in in vitro studies. ${ }^{9,26,36-38}$ This finding suggests that even though the in vitro data gives us a good idea about the expected aerosol delivery, it is essential to extend to an in vivo study due to the possible effects of human physiology. In addition, comparing in vivo to ex vivo

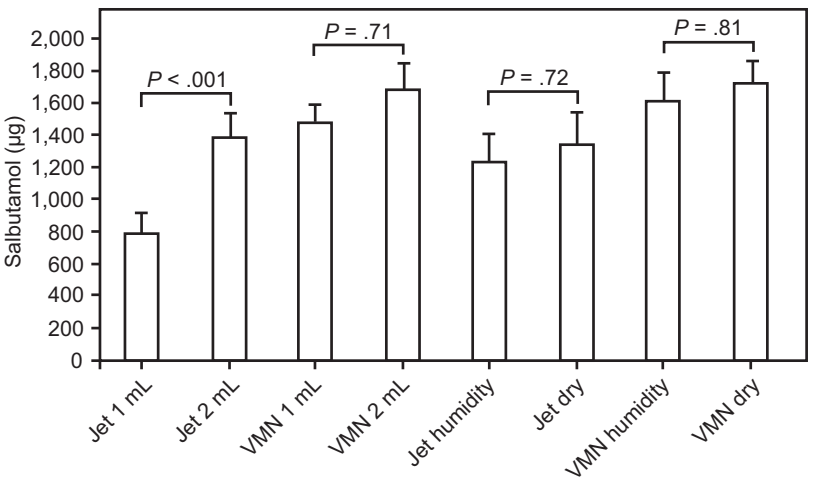

Fig. 5. Mean amount of salbutamol desorbed from ex-vivo filter. VMN $=$ vibrating mesh nebulizer.

data were not possible using normal statistical methods and would not provide accurate results due to the small number of patients used in the study. Further studies are needed to properly define the correlation between in vivo, ex vivo, and in vitro methodology. ${ }^{39}$

On the other hand, fill-volume change affected nebulization time, in that the increase in nebulization time due to volume change was observed with both nebulizers. ${ }^{24,26,40}$ This increased nebulization time might not be of importance in aerosol delivery to NIV patients unless it is a lifesaving medication delivered to critically ill patients. ${ }^{9}$ The dilution of $1-\mathrm{mL}$ respirable solution by $1-\mathrm{mL}$ saline in the jet nebulizer increased the drug delivery as measured with USAL24 by 2.9 -fold. This increase was much greater than that measured with USAL0.5, which was only 1.7 fold. Therefore, increasing the jet nebulizer fill volume results in better lung deposition, although this carries a much greater increase in systemic side effects, which must be considered when increasing the fill volume of jet nebulizer, especially in critically ill patients. ${ }^{41}$

Dilution of respirable solution in the jet nebulizer $(2-\mathrm{mL}$ fill volume) resulted in measurements with USAL24 and aerosol emitted comparable to those of the vibrating mesh nebulizer with no dilution (1-mL fill volume). However, the USAL 0.5 obtained with $1 \mathrm{~mL}$ delivered by the vibrat- 
Fill Volume, Humidity, AND Aerosol Delivery With NIV

Table 3. Salbutamol Delivered at Different Humidification Conditions

\begin{tabular}{|c|c|c|c|c|}
\hline Nebulizer Type & Fill Volume & USAL0.5, $\mu \mathrm{g}$ & USAL24, $\mu \mathrm{g}$ & Ex vivo, $\mu \mathrm{g}$ \\
\hline \multirow[t]{2}{*}{ Jet nebulizer } & With humidification & $59.1(26.4)$ & $376.6(156.3)$ & $1,231.3(180.2)$ \\
\hline & Without humidification & $54.8(22.6)$ & $405.2(160.5)$ & $1,352.6(193.2)$ \\
\hline$P$ & & .70 & .77 & .75 \\
\hline \multirow[t]{2}{*}{ Vibrating mesh nebulizer } & With humidification & $130.8(49.6)$ & $588.7(136.0)$ & $1,629.7(170.2)$ \\
\hline & Without humidification & $123.1(39.4)$ & $635.4(119.1)$ & $1,732.3(135.2)$ \\
\hline$P$ & & .89 & .72 & .86 \\
\hline $\begin{array}{l}\text { Data are shown as mean (SD). } \\
\text { USAL0.5 = unchanged salbutamol at } 30 \mathrm{~min}\end{array}$ & & \\
\hline
\end{tabular}

ing mesh nebulizer was still 2.3 -fold greater than results found with $2 \mathrm{~mL}$ delivered by a jet nebulizer. The vibrating mesh nebulizer did not need any dilution of the respirable solution to deliver significantly more aerosol to the lungs than the jet nebulizer. ${ }^{9,24,34}$ Based on better lung deposition by the vibrating mesh nebulizer and its short delivery time, we recommend that lifesaving aerosol medication, expensive drugs, and medication administered to critically ill patients should be delivered via vibrating mesh nebulizer without dilution to allow for a more efficient delivery in a very short time. It must be noted that our study was performed using respirable solutions, not suspensions or viscous medications. In addition, the cost of the vibrating mesh nebulizer compared to the disposable jet nebulizer may be an obstacle in some hospitals.

Although the humidity change results were far different from most of the previously published in vitro studies, which recommend switching off the humidifier when delivering aerosol to ventilated patients, $9,19,20,42-45$ the results were very close to our previous findings of the effects of humidity change on aerosol delivery in auto-CPAP ventilated subjects ${ }^{16}$ and invasively ventilated subjects. ${ }^{21,22}$ This finding shows that there is no need to discomfort the patient by switching off the humidifier for aerosol delivery because the dry gas could potentially be harmful to the lung and the increase in delivered aerosol was insignificant. In our study, the nebulizer was placed near the subject's mask in the single-limb ventilation circuit, similar to that of the auto-CPAP study and our in vitro study. ${ }^{16,26}$ This placement could decrease the effect of humidity on delivered aerosol compared to most of the previous in vitro studies in dual-limb ventilation circuit, in which the nebulizer was placed in the inspiratory limb far from the subject.9,19,20,45 However, our studies on dual-limb ventilated subjects also showed an insignificant difference between humidified and non-humidified aerosol delivery. ${ }^{21,22}$ This suggests that delivering aerosol during ventilation is not affected by the humidifier being on or off. All of the previous in vitro studies ignored the humidity of the air exhaled by the patient and the humidity of the ventilation circuit itself, which has been shown to persist for $30 \mathrm{~min}$ after turning off the humidifier. ${ }^{46}$ Based on our findings, we do not recommend interrupting humidification during aerosol delivery, especially after 2 reports found no significant effect on subjects' clinical status ${ }^{22}$ and aerosol delivery ${ }^{21}$ with changing humidity during aerosol administration to invasively ventilated subjects.

In addition to this study, we found in other research that humidity had no effect on aerosol delivery. ${ }^{16,21,22}$ This information could help optimize aerosol delivery for mechanically ventilated patients and avoid discontinuing humidity without benefit, given that switching off the humidifier may contribute to problems associated with administration of dry cold gas to the lungs, such as lung irritation, bronchospasm, and desiccation of secretions. ${ }^{47}$ These risks are greater if the clinician forgets to turn on the humidifier again after aerosol delivery.

\section{Limitations of the Study}

There are several important limitations of our study. Subjects' respiratory efforts were not quantified because, according to routine ward management of these patients, spirometry was not measured. The coefficient of variation for urinary salbutamol was reported to be approximately high, which may account for some of the insignificant differences. A potential limitation is that we operated the jet nebulizer at $1 \mathrm{~mL}$, which is lower than the recommended loading volumes, to compare it to the vibrating mesh nebulizer, which does not need dilution for aerosol delivery.

\section{Conclusion}

The effect of humidification on aerosol delivery in single-limb NIV was found to be statistically insignificant. We recommend keeping the humidifier on and at the same setting while delivering aerosol to NIV patients. At the same fill volume and humidification conditions, the vibrating mesh nebulizer resulted in better lung deposition 
and systemic absorption with shorter nebulization times than the jet nebulizer, indicating higher efficacy of the vibrating mesh nebulizer. Increasing fill volume is an essential factor for improving aerosol delivery via the jet nebulizer to the extent that a $2-\mathrm{mL}$ fill volume in the jet nebulizer had aerosol emitted and USAL24 measurements similar to those found with a $1-\mathrm{mL}$ fill volume in the vibrating mesh nebulizer. The vibrating mesh nebulizer is not significantly affected by increasing fill volume.

\section{ACKNOWLEDGMENTS}

Ms Patricia A Dailey, a Medical Science Liaison with Aerogen, provided help in English editing and aerosol science expertise for the development of the manuscript. Mr Mohammed RA-A Ali provided statistical assistance.

\section{REFERENCES}

1. Antonelli M, Conti G, Rocco M, Bufi M, De Blasi RA, Vivino G, et al. A comparison of noninvasive positive-pressure ventilation and conventional mechanical ventilation in patients with acute respiratory failure. N Engl J Med 1998;339(7):429-435.

2. Nava S, Navalesi P, Conti G. Time of non-invasive ventilation. Intensive care medicine 2006;32(3):361-370.

3. Chiumello D, Chevallard G, Gregoretti C. Non-invasive ventilation in postoperative patients: a systematic review. Intensive care medicine 2011;37(6):918-929.

4. Dhand R. Aerosol therapy in patients receiving noninvasive positive pressure ventilation. J Aerosol Med Pulm Drug Deliv 2012;25(2): 63-78.

5. Ehrmann S, Roche-Campo F, Papa GFS, Isabey D, Brochard L, Apiou-Sbirlea G. Aerosol therapy during mechanical ventilation: an international survey. Intensive Care Med 2013;39(6):1048-1056.

6. Hess DR. Aerosol therapy during noninvasive ventilation or highflow nasal cannula. Respir Care 2015;60(6):880-893.

7. Longest PW, Golshahi L, Hindle M. Improving pharmaceutical aerosol delivery during noninvasive ventilation: effects of streamlined components. Ann Biomed Eng 2013;41(6):1217-1232.

8. Dhand R. Aerosol delivery during mechanical ventilation: from basic techniques to new devices. J Aerosol Med Pulm Drug Deliv 2008; 21(1):45-60.

9. Ari A, Atalay OT, Harwood R, Sheard MM, Aljamhan EA, Fink JB. Influence of nebulizer type, position, and bias flow on aerosol drug delivery in simulated pediatric and adult lung models during mechanical ventilation. Respir Care 2010;55(7):845-851.

10. Abdelrahim M, Plant P, Chrystyn $\mathrm{H}$. The relative lung and systemic bioavailability of terbutaline following nebulisation in non-invasively ventilated patients. Int J Pharm 2011;420(2):313-318.

11. Abdelrahim ME, Plant $P$, Chrystyn H. In-vitro characterisation of the nebulised dose during non-invasive ventilation. J Pharm Pharmacol 2010;62(8):966-972.

12. ElHansy MHE, Boules ME, Farid H, Chrystyn H, El-Maraghi SK, Al-Kholy MB, et al. In vitro aerodynamic characteristics of aerosol delivered from different inhalation methods in mechanical ventilation. Pharm Dev Technol 2017;22(6):844-849.

13. Hassan A, Rabea H, Hussein RRS, Salah Eldin R, Abdelrahman MM, Said ASA, et al. In-vitro characterization of the aerosolized dose during non-invasive automatic continuous positive airway pressure ventilation. Pulm Ther 2016;2(1):115-126.

14. Hassan A, Salah Eldin R, Abdelrahman MM, Abdelrahim ME. Invitro/in-vivo comparison of inhaled salbutamol dose delivered by jet nebulizer, vibrating mesh nebulizer and metered dose inhaler with spacer during non-invasive ventilation. Exp Lung Res 2017;43(1): 19-28.

15. Hussein RRS, Ali AMA, Salem HF, Abdelrahman MM, Said ASA, Abdelrahim MEA. In vitro/in vivo correlation and modeling of emitted dose and lung deposition of inhaled salbutamol from metered dose inhalers with different types of spacers in noninvasively ventilated patients. Pharm Dev Technol 2017;22(7):871-880.

16. Mohsen M, Elberry AE, Salah Eldin A, Hussein RR, Abdelrahim EM. Effects of heat and humidification on aerosol delivery during auto-CPAP noninvasive ventilation. Arch Pulmonol Respir Care 2017;3(1):11-15.

17. Rabea H, Ali AMA, Salah Eldin R, Abdelrahman MM, Said ASA, Abdelrahim ME. Modelling of in-vitro and in-vivo performance of aerosol emitted from different vibrating mesh nebulisers in noninvasive ventilation circuit. Eur J Pharm Sci 2017;97:182-191.

18. Sarhan RM, Elberry AA, Abdelwahab NS, Rabea H, Salem MN, Abdelrahim MEA. Effect of a nebulizer holding chamber on aerosol delivery. Respir Care, in press.

19. Lange CF, Finlay WH. Overcoming the adverse effect of humidity in aerosol delivery via pressurized metered-dose inhalers during mechanical ventilation. Am J Respir Crit Care Med 2000;161(5):16141618.

20. Ari A, Areabi H, Fink J. Evaluation of aerosol generator devices at 3 locations in humidified and non-humidified circuits during adult mechanical ventilation. Respir Care 2010;55(7):837-844.

21. Moustafa IOF, Ali MRA, Al Hallag M, Rabea H, Fink JB, Dailey P, Abdelrahim MEA. Lung deposition and systemic bioavailability of different aerosol devices with and without humidification in mechanically ventilated patients. Heart Lung 2017;46(6):464-467.

22. Moustafa IOF, ElHansy MHE, Al Hallag M, Fink JB, Dailey P, Rabea H, Abdelrahim MEA. Clinical outcome associated with the use of different inhalation method with and without humidification in asthmatic mechanically ventilated patients. Pulm Pharmacol Ther 2017;45:40-46.

23. Tuggey JM, Delmastro M, Elliott MW. The effect of mouth leak and humidification during nasal non-invasive ventilation. Respir Med 2007;101(9): 1874-1879.

24. Clay MM, Pavia D, Newman SP, Clarke SW. Factors influencing the size distribution of aerosols from jet nebulisers. Thorax 1983;38(10): 755-759.

25. Saeed H, Elberry AA, Eldin AS, Rabea H, Abdelrahim MEA. Effect of nebulizer designs on aerosol delivery during non-invasive mechanical ventilation: a modeling study of in vitro data. Pulm Ther 2017;3(1):233-241.

26. Saeed H, Mohsen M, Fink JB, Dailey P, Salah Eldin A, Abdelrahman MM, et al. Fill volume, humidification and heat effects on aerosol delivery and fugitive emissions during noninvasive ventilation. J Drug Deliv Sci Technol 2017;39:372-378.

27. Hindle M, Chrystyn H. Determination of the relative bioavailability of salbutamol to the lung following inhalation. Br J Clin Pharmacol 1992;34(4):311-315.

28. Silkstone V, Dennis J, Pieron C, Chrystyn H. An investigation of in vitro/in vivo correlations for salbutamol nebulized by eight systems. J Aerosol Med 2002;15(3):251-259.

29. Mazhar SH, Ismail NE, Newton DA, Chrystyn H. Relative lung deposition of salbutamol following inhalation from a spacer and a Sidestream jet nebulizer following an acute exacerbation. Br J Clin Pharmacol 2008;65(3):334-337.

30. Dai B, Kang J, Sun L-f, Tan W, Zhao H-w. Influence of exhalation valve and nebulizer position on albuterol delivery during noninvasive positive pressure ventilation. J Aerosol Med Pulm Drug Deliv 2014;27(2):125-132.

31. ElHansy MHE, Boules ME, El-Essawy AFM, Al-Kholy MB, Abdelrahman MM, Said ASA, et al. Inhaled salbutamol dose delivered 


\section{Fill Volume, Humidity, AND Aerosol Delivery With NIV}

by jet nebulizer, vibrating mesh nebulizer and metered dose inhaler with spacer during invasive mechanical ventilation. Pulm Pharmacol Ther 2017;45:159-163.

32. Harb HS, Elberry AA, Rabea H, Fathy M, Abdelrahim MEA. Is Combihaler usable for aerosol delivery in single limb non-invasive mechanical ventilation? J Drug Delivery Sci Technol 2017;40:28-34.

33. Madney YM, Fathy M, Elberry AA, Rabea H, Abdelrahim MEA. Nebulizers and spacers for aerosol delivery through adult nasal cannula at low oxygen flow rate: an in-vitro study. J Drug Deliv Sci Technol 2017;39:260-265.

34. Phillips G, Millard F. The therapeutic use of ultrasonic nebulizers in acute asthma. Respiratory Medicine 1994;88(5):387-389.

35. Carvalho TC, McConville JT. The function and performance of aqueous aerosol devices for inhalation therapy. J Pharm Pharmacol 2016; 68(5):556-578.

36. Berlinski A, Willis JR. Albuterol delivery by 4 different nebulizers placed in 4 different positions in a pediatric ventilator in vitro model. Respir Care 2013;58(7):1124-1133.

37. Pitance L, Vecellio L, Leal T, Reychler G, Reychler H, Liistro G. Delivery efficacy of a vibrating mesh nebulizer and a jet nebulizer under different configurations. J Aerosol Med Pulm Drug Deliv 2010;23(6):389-396.

38. Michotte J-B, Jossen E, Roeseler J, Liistro G, Reychler G. In vitro comparison of five nebulizers during noninvasive ventilation: analysis of inhaled and lost doses. J Aerosol Med Pulm Drug Deliv 2014;27(6):430-440.

39. Saeed H, Ali AMA, Elberry AA, Eldin AS, Rabea H, Abdelrahim MEA. Modeling and optimization of nebulizers' performance in noninvasive ventilation using different fill volumes: comparative study between vibrating mesh and jet nebulizers. Pulm Pharmac Ther 2018; 50:62-71.

40. Geller DE. The science of aerosol delivery in cystic fibrosis. Pediatr Pulm 2008;43(S9):S5-S17.

41. Boe J, Dennis JH, O'Driscoll BR, Bauer TT, Carone M, Dautzenberg, B, et al. European Respiratory Society Guidelines on the use of nebulizers. Eur Respir J 2001;18(1):228-242.

42. Thille AW, Bertholon J-F, Becquemin M-H, Roy M, Lyazidi A, Lellouche $\mathrm{F}$, et al. Aerosol delivery and humidification with the Boussignac continuous positive airway pressure device. Respir Care 2011;56(10):1526-1532.

43. Miller DD, Amin MM, Palmer LB, Shah AR, Smaldone GC. Aerosol delivery and modern mechanical ventilation: in vitro/in vivo evaluation. Am J Respir Crit Care Med 2003;168(10):1205-1209.

44. Dhand R, Mercier E. Effective inhaled drug administration to mechanically ventilated patients. Expert Opin Drug Deliv 2007;4(1): 47-61.

45. Ari A, Harwood R, Sheard M, Alquaimi MM, Alhamad B, Fink JB. Quantifying aerosol delivery in simulated spontaneously breathing patients with tracheostomy using different humidification systems with or without exhaled humidity. Respir Care 2016;61(5):600-606.

46. Lin H-L, Fink JB, Zhou Y, Cheng Y-S. Influence of moisture accumulation in inline spacer on delivery of aerosol using metered-dose inhaler during mechanical ventilation. Respir Care 2009;54(10):13361341.

47. Branson RD, Gentile MA. Is humidification always necessary during noninvasive ventilation in the hospital? Respir Care 2010;55(2):209216. 